\title{
Refractive error and visual impairment in primary school children in Onitsha, Anambra State, Nigeria
}

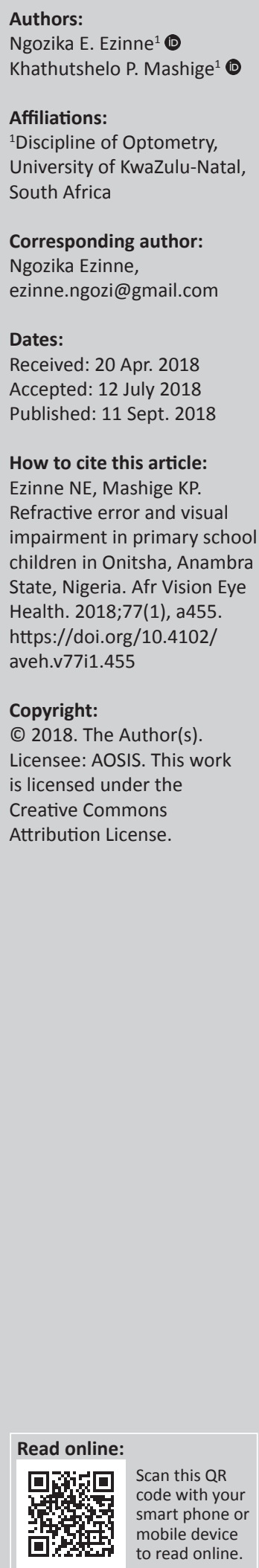

Background: Vision problems have been shown to adversely affect a child's achievement in school.

Aim: To determine the prevalence of refractive error and visual impairment in primary school children in Onitsha, Anambra State, Nigeria.

Setting: The study was conducted in a primary school in Onitsha, Anambra State, Nigeria.

Methods: A stratified random cluster sampling method was used to select primary school children aged between 5 and 15 years from grades 1 to 6 in primary schools in Onitsha North and South. A total of 1020 children in 102 clusters were enumerated and 998 (97.8\%) were examined. The examination included visual acuity measurements, ocular motilities, retinoscopy and autorefraction under cycloplegia, and examination of the anterior segment, media and fundae.

Results: The prevalence of uncorrected, presenting and best corrected visual acuity of 20/40 or worse in the better eye was $9.7 \%, 7.7 \%$ and $1.3 \%$, respectively. Refractive error accounted for $86.6 \%$ of all causes of visual impairment. Myopia was the most prevalent refractive error $(46.4 \%)$, followed by astigmatism (36.1\%) and hyperopia (17.5\%). Refractive error and visual impairment were significantly more prevalent in females than in males $(p=0.04)$. Refractive error was highest among children aged between 11 and 13 years, while visual impairment was greatest among children aged between 5 and 7 years.

Conclusion: The prevalence of refractive error and visual impairment among primary school children in Onitsha was relatively high, highlighting the need for services and strategies to address these conditions in that area.

\section{Introduction}

Refractive error (RE) is an optical defect of the eye that prevents parallel light rays from being brought to a clear focus on the retina and is a common cause of visual impairment (VI) and blindness worldwide. ${ }^{1}$ It is estimated that 2.3 billion people live with RE globally. ${ }^{2}$ In 2006, 153 million people had uncorrected refractive error (URE) of whom 13 million were children and 45 million were visually impaired. ${ }^{3,4}$ The resulting VI can lead to health, socio-economic and quality-of-life implications. ${ }^{1}$ In addition, $90 \%$ of people with URE live in developing countries such as Nigeria. ${ }^{5}$ Refractive errors can be easily and effectively corrected with a pair of spectacles, contact lenses or refractive surgery, with spectacles being the most common and cost-effective form of correction.

Studies on the prevalence of RE and VI have been conducted in various provinces of Nigeria, such as Western, ${ }^{6}$ Northern, ${ }^{7}$ Southeastern ${ }^{8}$ and South-South, ${ }^{9}$ and have yielded different results. Many of these studies have documented region-specific prevalence and causes of VI, with most being conducted on older children and adults. There is a need for local studies to ascertain the prevalence of RE and VI peculiar to children in each community, as this varies from one locality to another for a variety of reasons. These factors include tribal, ethnic, geographical and socio-economical differences, which may have an impact on RE and VI. The aim of this study was to determine the prevalence of RE and VI in Onitsha, Anambra State, Nigeria. Data on RE and VI will be useful for planning, implementing and monitoring refraction and other eye care services in this group. In addition, the information can be used as baseline data for evaluating existing RE and VI programmes in this region.

\section{Methods}

Onitsha is an urban area located on the eastern bank of the Niger River in Anambra State, Eastern Nigeria. The study population was primary school children from all the private and 
public schools in Onitsha North and South, the estimated pupil school population being 13296 in 2009 which was projected to be 15324 by the year 2017.10 A multistage sampling method was used to select school children in the study population and the baseline sample size was determined using the equation ${ }^{11}$ :

$$
N=(Z)^{2}(1.0-P)(P) /([B][P])^{2}
$$

where $P$ is the anticipated prevalence of RE, $B$ is the desired error bound $(10 \%)$ and $Z=1.96 \%$ confidence interval. The prevalence estimates from previous studies conducted in Nigeria ranged between $7.3 \%$ and $22.5 \% .{ }^{12} \mathrm{~A} 15 \%$ prevalence rate, which is the average of the prevalence estimates from previous studies, was used. The minimum sample size required was, therefore, calculated to be 968, which was increased to 1000 to adjust for anticipated absenteeism and non-participation rate, which should not exceed $10 \%$, to ensure minimal bias in the study results.

Children aged between 5 and 15 years whose parents or legal guardians provided informed consent were included in the study. The other inclusion criteria were children who gave verbal assent and/or signed assent, children who were Nigerian citizens, as indicated by the class register and the class teacher. Children younger than 5 years and older than 15 years, those who were not Nigerian citizens and those whose parents or legal guardians could not provide informed consent were excluded from the study. Ethical approval to conduct the study was obtained from the University of KwaZulu-Natal's Biomedical Research and Ethics Committee (BE620/16) and Onitsha Zone Education boards. The research protocol adhered to the provisions of the Declaration of Helsinki for research involving human subjects. The heads of the identified schools were contacted to request their permission to engage with the children in their schools. Each school provided a room in which the equipment could be set up for testing, and the teachers were informed that the children would be called out of class to have their eyes tested in the assigned rooms.

\section{Clinical examination}

Clinical examinations were conducted by five optometrists in the 17 selected primary schools in Onitsha North and South Local Government Area in Anambra State, Nigeria. Examination procedures followed the original Refractive Error Study in Children (RESC) protocol..$^{11}$ In brief, distance visual acuity (VA) was measured with a retro-illuminated $\log$ MAR chart with five optotypes on each line (Precision Vision, Villa Park, Illinois). Ocular deviations were evaluated with a cover test at both distance and near. Heterotropias were categorised as exotropia, esotropia and vertical and the degree of tropia measured using corneal light reflex and neutralising prisms.

Examination of the anterior segment was performed with a pen torch. In children with unaided VA of 20/40 or worse in either eye, cycloplegic drops were used: two drops of $1 \%$ cyclopentolate eye drops administered 15 minutes apart. After $20 \mathrm{~min}$, if a pupillary light reflex was still present, a third drop was administered. The light reflex and pupil dilation were checked after an additional $15 \mathrm{~min}$. Cycloplegia was considered complete if the pupil dilated to $6 \mathrm{~mm}$ or greater and a light reflex was absent. Cycloplegic refraction was carried out first using a streak retinoscope (Welch-Allyn, Skaneateles, United States) in a semi-dark room at a distance of $67 \mathrm{~cm}$ and $\mathrm{a}+1.50 \mathrm{D}$ lens in the trial frame and then with an auto-refractor (Retinomax K-Plus; Nikon, Tokyo, Japan) according to the manufacturer's instructions. The autorefractor was calibrated daily by a technician, and a minimum of five readings with valid confidence rankings were obtained for each eye. Using the objective refraction measurement as the starting point (when available), best corrected VA with subjective refraction was determined using the trial frame. Refractive error was assigned as the cause of VI if acuity improves to $20 / 32$ or better with subjective refractive correction with or without pinhole.

Examination of the crystalline lens, vitreous and fundus was performed with a direct ophthalmoscope (Welch-Allyn, Skaneateles, United States) in children who had an unaided VA of 20/40 or worse in either eye to ascertain the cause of the VI.

\section{Pilot study}

Prior to the main study, a pilot study was conducted among 50 primary school children outside the study area to check the appropriateness of the study procedures, methods and logistics. All queries that arose from the pilot study were addressed, and the procedures were modified accordingly before the main study was performed.

\section{Definition of terms}

Uncorrected VA of 20/40 or less was regarded as mainly because of URE, and best corrected VA of 20/40 or worse was regarded as VI. Thresholds of 20/40 or less, less than 20/63 and 20/200 or less were used in defining visual categories. Myopia was defined as RE of at least $-0.50 \mathrm{D}$, hyperopia as $2 \mathrm{D}$ or more and astigmatism as $-0.50 \mathrm{D}$ or more using subjective refraction.

\section{Data management and analysis}

Class enumeration and clinical examination data forms were reviewed for completeness in the field before they were captured into the computer. Assistance of a statistician was sought for the data analysis, which was analysed using descriptive and inferential statistics in the Statistical Package for Social Sciences (SPSS) version 24. Ranges, means, standard deviations, frequencies and correlations were determined. Chisquare and Pearson's correlation tests were used to investigate relationships between age and gender with VI and RE.

\section{Ethical consideration}

The study was approved by the Biomedical Research and Ethics Committee, University of KwaZulu-Natal, the 
Department of Education and Training, and the heads of the identified schools, Onitsha, Nigeria, and the study adhered to the tenets of the Declaration of Helsinki.

\section{Results}

Of the 1020 primary school children aged between 5 and 15 years from 17 primary schools in Onitsha North and South who were enumerated, $998(97.8 \%)$ participated in the study. The participants included 443 (44.4\%) males and 555 (55.6\%) females (Figure 1). Their mean age was $9.01 \pm 2.5$ years and 389 (39\%) were aged between 8 and 10 years.

\section{Visual acuity}

Of the 998 children examined, uncorrected VA of 20/32 or better in the better eye was found in 901 (90.3\%) children, $97(9.7 \%)$ had uncorrected VA of $20 / 40$ or worse in the better eye and 20 (2\%) wore spectacles. Eighty-four (86.6\%) children improved to $\geq 20 / 32$ in the better eye after refraction and $13(13.4 \%)$ had best corrected VA of $20 / 40$ or worse in the better eye, including one child (1\%) with no light perception in one eye. This results in the prevalence of uncorrected VA of 20/40 or worse in the better eye of $9.7 \%$, of presenting VA of $7.7 \%$, and best corrected of $1.3 \%$ (Table 1).

\section{Refractive error}

Ninety-seven (9.7\%) children who had VA of 20/40 or worse in either eye underwent cycloplegic refraction. Complete

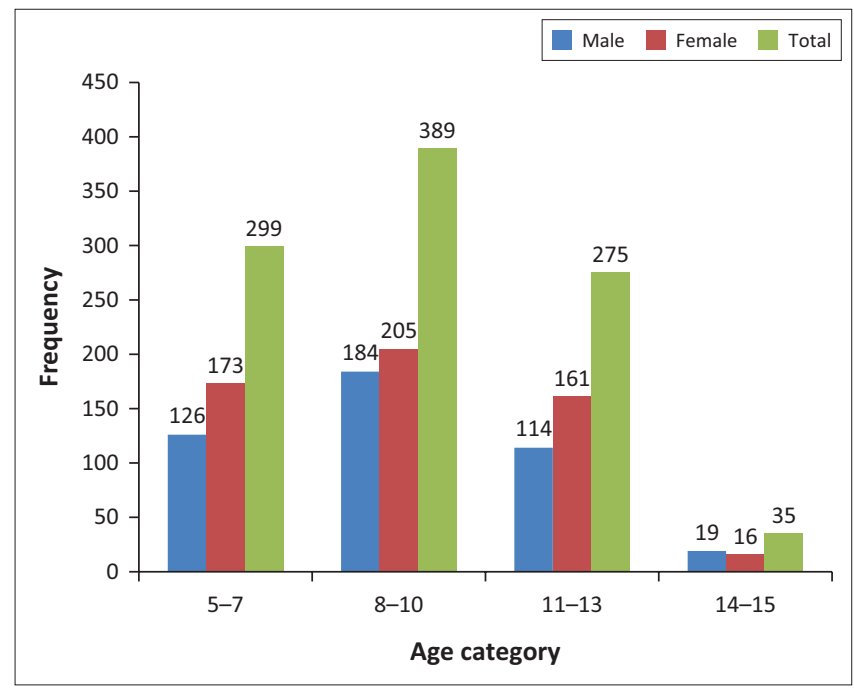

FIGURE 1: Demographic profiles of enumerated study population. cycloplegia was achieved in 85 (87.6\%) right eyes and 79 (81.4\%) left eyes. However, pupil dilation with light reflexes present was found in $11(11.3 \%)$ right eyes and 9 (9.3\%) left eyes, while the absence of light reflex without full pupil dilation was found in $12(12.4 \%)$ right eyes and $18(18.6 \%)$ left eyes. Therefore, $72(74.2 \%)$ children satisfied one or both criteria for cycloplegia dilation in both eyes.

Hyperopia ranged from $+1 \mathrm{D}$ to $5 \mathrm{D}$ with retinoscopy and from $+1 \mathrm{D}$ to $5 \mathrm{D}$ with auto-refraction. Both retinoscopy and auto-refraction values showed that hyperopia decreased with increasing age and was highest among children 5-7 years old. Myopia ranged from $-1 \mathrm{D}$ to $-11 \mathrm{D}$ with retinoscopy and $-1 \mathrm{D}$ to $-11.50 \mathrm{D}$ with auto-refraction. Myopia increased with increasing age and was highest among children aged between 11 and 13 years, and between 14 and 15 years. Astigmatism of $-0.50 \mathrm{D}$ to $-1.75 \mathrm{D}$ was found in $24(24.7 \%)$ right eyes and $37(38 \%)$ left eyes with retinoscopy and $25(25.8 \%)$ right eyes and 38 (39.2\%) left eyes with autorefraction. Astigmatism of $\geq 2 \mathrm{D}$ was found in 4 (4.1\%) right eyes and $5(5.2 \%)$ left eyes with retinoscopy, and $4(4.1 \%)$ right eyes and $6(6.2 \%)$ left eyes with auto-refraction. These results indicate that significant astigmatism in either eye was present in $35(36.1 \%)$ children. The prevalence of hyperopia ranged between $17.5 \%$ and $21.6 \%$ when measured with retinoscopy and auto-refraction, respectively. With retinoscopy, the prevalence of myopia ranged from $6.2 \%$ in 5- to 7 -year-olds to $15.5 \%$ in 8 - to 10 -year-olds (Table 2). With auto-refraction, the prevalence of myopia was $49.5 \%$, while auto-refraction and retinoscopy results could not be obtained in $21(21.6 \%)$ eyes because of poor co-operation, fixation and claustrophobia.

Of the 97 children who had RE, 45 (46.4\%) had myopia, $35(36.1 \%)$ had astigmatism and 17 (17.5\%) had hyperopia (Figure 2). Forty-two (43.3\%) children who had RE were males, while RE was highest (45.4\%) among the 11- to 13-yearolds and least common (4.1\%) among children aged between 14 and 15 years (Figure 3). Refractive error was found to be

TABLE 2: Retinoscopy and auto-refraction.

\begin{tabular}{|c|c|c|c|c|c|}
\hline \multirow{2}{*}{$\begin{array}{l}\text { Age } \\
\text { (years) }\end{array}$} & \multirow{2}{*}{$\begin{array}{l}\text { Number } \\
\text { of } \\
\text { children }\end{array}$} & \multicolumn{2}{|c|}{ Hyperopia } & \multicolumn{2}{|c|}{ Myopia } \\
\hline & & Retinoscopy & Auto-refraction & Retinoscopy & Auto-refraction \\
\hline $5-7$ & 15 & $+1 \mathrm{D}-+4 \mathrm{D}$ & $+1 \mathrm{D}-+5 \mathrm{D}$ & $-1 D--4 D$ & $-2 D--5 D$ \\
\hline $8-10$ & 34 & $+0.5 \mathrm{D}-+3 \mathrm{D}$ & $+1 D-+4 D$ & $-0.5 \mathrm{D}--10 \mathrm{D}$ & $-1 \mathrm{D}--10.5 \mathrm{D}$ \\
\hline $11-13$ & 44 & $+1 \mathrm{D}-2.5 \mathrm{D}$ & $+1 \mathrm{D}-+3.5 \mathrm{D}$ & $-1 D--11 D$ & $-2 \mathrm{D}--11.5 \mathrm{D}$ \\
\hline $14-15$ & 4 & $+0.5 \mathrm{D}-+2 \mathrm{D}$ & $+1 \mathrm{D}-+2.5 \mathrm{D}$ & $-0.5 \mathrm{D}--11 \mathrm{D}$ & $-1 \mathrm{D}--11.5 \mathrm{D}$ \\
\hline Total & 97 & - & - & - & - \\
\hline
\end{tabular}

D, Dioptre

TABLE 1: Distribution of uncorrected, presenting and best corrected visual acuity.

\begin{tabular}{|c|c|c|c|c|c|c|c|c|}
\hline \multirow[t]{2}{*}{ VA category } & \multicolumn{2}{|c|}{ Uncorrected VA } & \multicolumn{2}{|c|}{ Wearing glasses } & \multicolumn{2}{|c|}{ Presenting VA } & \multicolumn{2}{|c|}{ Best corrected VA } \\
\hline & $N$ & $\%$ & $N$ & $\%$ & $N$ & $\%$ & $N$ & $\%$ \\
\hline$\geq 20 / 32$ in both eyes & 891 & 89.3 & 0 & - & 891 & 89.3 & 980 & 98.2 \\
\hline$\geq 20 / 32$ in one eye only & 10 & 1.00 & 0 & - & 30 & 3.0 & 5 & 0.5 \\
\hline$\leq 20 / 40$ to $20 / 63$ or better in the better eye & 58 & 5.8 & 7 & 0.7 & 51 & 5.1 & 11 & 1.1 \\
\hline$\leq 20 / 80$ to $20 / 160$ or better in the better eye & 35 & 3.5 & 10 & 1.0 & 25 & 2.5 & 2 & 0.2 \\
\hline$\leq 20 / 200$ or worse in the better eye & 4 & 0.4 & 3 & 0.3 & 1 & 0.1 & 0 & - \\
\hline Total & 998 & 100.0 & 20 & 2.0 & 998 & 100.0 & 998 & 100.0 \\
\hline
\end{tabular}

VA, visual acuity; $N$, number. 


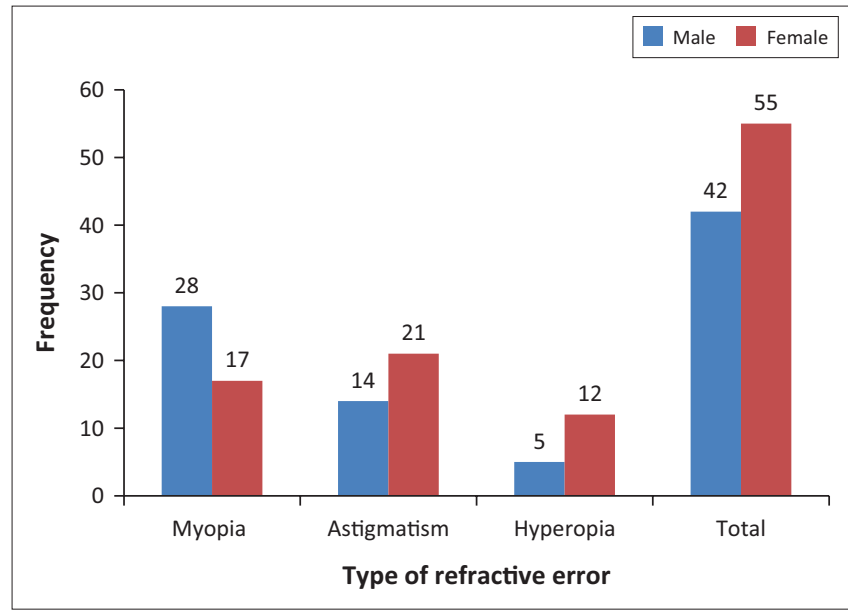

FIGURE 2: Distribution of refractive error by gender.

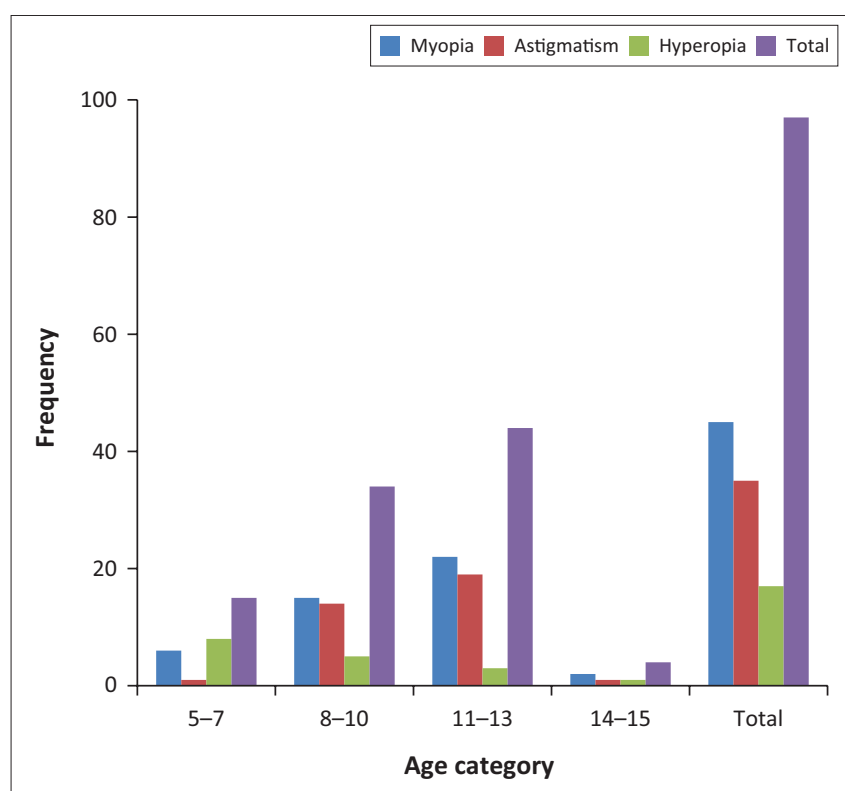

FIGURE 3: Distribution of refractive error by age group.

TABLE 3: Distribution of types of astigmatism.

\begin{tabular}{|c|c|c|c|c|c|c|c|c|}
\hline \multirow[t]{2}{*}{ Eye } & \multicolumn{2}{|c|}{ With-the-rule } & \multicolumn{2}{|c|}{ Against-the-rule } & \multicolumn{2}{|c|}{ Oblique } & \multicolumn{2}{|c|}{ Total } \\
\hline & $n$ & $\%$ & $n$ & $\%$ & $n$ & $\%$ & $n$ & $\%$ \\
\hline Right eyes & 16 & 57.1 & 5 & 17.9 & 7 & 25.0 & 28 & 100.0 \\
\hline Left eyes & 25 & 59.5 & 12 & 35.7 & 5 & 4.8 & 42 & 100.0 \\
\hline Total & 41 & 58.6 & 17 & 24.3 & 12 & 17.1 & 70 & 100.0 \\
\hline
\end{tabular}

$n$, number.

significantly associated with age (Pearson's $\chi^{2}=13.13$, $p=0.00$ ) and gender (Pearson's $\chi^{2}=4.17, p=0.04$ ). Myopia was significantly associated with males $(p=0.03)$ but not with age. Astigmatism and hyperopia were not significantly associated with age and gender (all $p$-values $>0.05$ ).

Out of 70 eyes of 35 children with astigmatism, 41 (58.6\%) eyes had with-the-rule (WTR) astigmatism (Table 3).

\section{Ocular anomalies}

Exotropia accounted for the highest proportion of deviations and tropia with near fixation, being present in 19 (1.9\%) of the
TABLE 4: Causes of visual impairment.

\begin{tabular}{lcc}
\hline Cause of VI & $\boldsymbol{N}$ & $\mathbf{\%}$ \\
\hline Refractive error & 84 & 86.6 \\
Retinal disorder & 4 & 4.1 \\
Cornea opacity & 2 & 2.1 \\
Amblyopia & 4 & 4.1 \\
Albinism & 3 & 3.1 \\
\hline Total & $\mathbf{9 7}$ & $\mathbf{1 0 0 . 0}$ \\
\hline
\end{tabular}

$\mathrm{VI}$, visual impairment; $N$, number.

998 children examined and in $10(1 \%)$ with distant fixation. Twenty-one $(72.4 \%)$ of the tropias detected were exotropia at near, with one quarter $(23 \%)$ of the children being exophoric at near. The exterior and anterior segment abnormalities were observed in $61(6 \%)$ of the 998 children examined. Eyelid abnormalities were present in 15 eyes of $10(1 \%)$ children. Conjunctival abnormalities were present in 80 eyes of $42(4.2 \%)$ children. Corneal abnormalities, mainly opacities, were found in two eyes of two $(0.2 \%)$ children, and an abnormal lens was observed in one $(1 \%)$ child. Fundus abnormalities, including optic atrophy, macular and retinal degenerations, were present in 8 eyes of 12 (1.2\%) children, while $2(0.2 \%)$ had micro-ophthalmos.

\section{Causes of visual impairment}

Of the 97 children with uncorrected VA of 20/40 or worse in the better eye, $84(86.6 \%)$ were because of URE and thus improved to $\geq 20 / 32$ after refraction, while 13 (13.4\%) could not be improved to $\geq 20 / 32$ in the better eye. The prevalence of VI (best corrected VA of 20/40 or worse in the better eye) was therefore 13 (1.3\%) (Table 4).

Nine (69.2\%) children who had VI were females and 4 (30.8\%) and $11(84.6 \%)$ children were aged between 5 and 7 years, $2(15.4 \%)$ children were aged between 8 and 10 years and no VI was found in children older than 11 years. Visual impairment was found to be significantly associated with age (Pearson's $\chi^{2}=19.36, p=0.00$ ) but not with gender (Pearson's $\chi^{2}=1.004, p=0.32$ ).

\section{Discussion}

Except for a relatively large number of 8- to 10-year-olds and a small number of 15-year-olds, the age distribution of the enumerated population was reasonably uniform. The high response rate in this study could be in part, owing to the fact that there are no school eye screening programmes in Onitsha, so the children felt it was an opportunity to get their eyes tested. The endorsements by the education board secretaries, co-operation of the class teachers and ParentTeacher Association (PTA) also contributed to the high response rate.

The prevalence of RE among primary school children aged between 5 and 15 years tested in Onitsha, Anambra state was 9.7\%. This falls within the World Health Organization (WHO) prevalence range of $2 \%-10 \%$ reported among children in this age group worldwide and warrants regular vision screening. Table $5^{6,7,8,9,13,14,15,16,17,18,19,20,21,22,23,24,25,26,27}$ provides an overview of 
TABLE 5: Prevalence of refractive error studies in children in Africa.

\begin{tabular}{|c|c|c|c|c|c|c|c|c|}
\hline Author & Country & Year & Age (years) & Sample size & $\begin{array}{c}\text { Prevalence of } \\
\text { RE }(\%)\end{array}$ & Myopia (\%) & Hyperopia (\%) & Astigmatism (\%) \\
\hline This study & Nigeria & 2017 & $5-15$ & 998 & 9.7 & 4.5 & 1.7 & 3.5 \\
\hline Mohammed et al. & Egypt & 2014 & $6-10$ & 142 & 66.9 & 62.7 & 3.5 & 0.7 \\
\hline Gamal et al. & Egypt & 2015 & $6-15$ & 2070 & 29.4 & NR & NR & NR \\
\hline Nebiyat et al. & Ethiopia & 2015 & $6-19$ & 1800 & 4.0 & 2.7 & 0.6 & 0.8 \\
\hline Assefa et al. & Ethiopia & 2012 & $4-24$ & 1852 & 9.4 & 3 & 2.5 & 2.1 \\
\hline Kassa and Degu & Ethiopia & 2004 & $5-15$ & 1134 & 7.6 & 5.4 & 2.2 & NR \\
\hline Jafer and Abomesh & Ethiopia & 2009 & $7-15$ & 570 & 3.5 & 2.6 & 0.9 & NR \\
\hline Kumah et al. & Ghana & 2013 & $12-15$ & 2435 & 3.7 & 3.3 & 0.4 & NR \\
\hline Ovenseri and Omuemu & Ghana & 2010 & $5-19$ & 1103 & 25.6 & 6.9 & 4.6 & 14.1 \\
\hline Ovenseri and Assien & Ghana & 2010 & $11-18$ & 961 & 4.5 & 0.2 & 2.3 & 2.0 \\
\hline Muma et al. & Kenya & 2009 & $12-15$ & 1439 & 5.2 & 1.7 & 3.2 & 0.3 \\
\hline Msiska et al. & Malawi & 2009 & $12-15$ & 1278 & 2.4 & 1.4 & 0.8 & 0.1 \\
\hline Faderin and Ajaiyeoba & Nigeria & 2001 & $5-15$ & 919 & 7.3 & 0.9 & 5.2 & 1.2 \\
\hline Opubiriet et al. & Nigeria & 2013 & $4-15$ & 506 & 22.5 & 13.8 & 2.6 & 6.1 \\
\hline Opubiri and Egbe & Nigeria & 2013 & $5-15$ & 1242 & 2.2 & NR & NR & NR \\
\hline Balarabe et al. & Nigeria & 2015 & $11-20$ & 614 & 4.8 & 2.9 & 1.1 & 0.8 \\
\hline Megbalayin and Asana & Nigeria & 2013 & $9-21$ & 1175 & 6.9 & NR & NR & NR \\
\hline Ahuamaand Atowa & Nigeria & 2004 & $7-17$ & 2525 & 58 & 31.1 & 19.1 & 7.8 \\
\hline Semanyezi et al. & Rwanda & 2015 & $11-37$ & 634 & 18.9 & 10.2 & 4.3 & 4.4 \\
\hline Naidoo et al. & South Africa & 2003 & $5-15$ & 4890 & 1.4 & 0.9 & 0.5 & NR \\
\hline Atif et al. & Sudan & 2016 & $5-15$ & 183 & 2.2 & 1.3 & 0.1 & 0.8 \\
\hline Wedner et al. & Tanzania & 2000 & $7-19$ & 1386 & 0.7 & 0.1 & 0.5 & 0.1 \\
\hline Kawuma and Mayeku & Uganda & 2002 & $6-9$ & 623 & 11.6 & 2.7 & 3.7 & 5.2 \\
\hline
\end{tabular}

$\mathrm{RE}$, refractive error; NR, not reported.

selected studies on the prevalence of REs among children of various ages in a range of African countries.

The prevalence of $9.7 \%$ for URE is higher than the $2.2 \%$ reported in Bayelsa, Nigeria, ${ }^{9}$ but is comparable to that reported elsewhere in Nigeria, specifically the $7.3 \%$ and $8.7 \%$ in Lagos $^{28}$ as well as the $7.4 \%$ in Enugu ${ }^{29}$ and $8.9 \%{ }^{30}$ in Ibadan. However, the prevalence is lower than $22.5 \%$ and $58.0 \%$ reported in South-South Nigeria and Abia State, ${ }^{8}$ Nigeria, respectively. The low prevalence recorded in Bayelsa study could be because of the fact that it was a vision screening programme, and some children with low magnitude of RE and normal VA could have been missed. In addition, the current study was school-based while that of Opubiri et al. ${ }^{9}$ was hospital based among 4- to 15-year-olds, which could have accounted for this difference. It is well known that most hospital-based studies would generally record higher rates of conditions than in the general population. ${ }^{9}$ Furthermore, the sample size and different definitions used for RE could have accounted for the differences between them. For example, the current study used a sample size of 998 and VA of 20/40 or worse in the better eye for the definition of RE, while a sample size of 4225 and VA of 20/32 or worse were used in the study in Abia State. ${ }^{8}$

Comparison of the current study with studies in Africa shows that the prevalence of $9.7 \%$ for URE is close to $7.6 \%$ and $9.4 \%$ reported in Ethiopia (Table 5). The differences observed in the prevalence could be because of different operational definitions and methodologies considered by authors and differences in demographic variables. Moreover, lifestyle and environmental as well as genetic factors have been reported to contribute to variations in the prevalence of RE. ${ }^{31}$
Recently, increased outdoor activities and exposure to high light intensity, common among rural dwellers, have been suggested to be factors influencing the prevalence of RE in rural areas. ${ }^{32}$ On the contrary, lifestyle factors such as increased near work and indoor activities common among urban dwellers have also been known to increase the prevalence of RE in urban areas. ${ }^{32}$ However, other studies have shown the prevalence of RE to be high in urban and highly developed areas compared to rural and less developed areas. ${ }^{33}$ Although racial and ethnic differences are the most important reasons for differences in the prevalence of RE, studies have also shown that genetically determined factors (such as eye pigmentation) may theoretically interact with environmental influences (such as outdoor light exposure) to impact RE development in black people. ${ }^{2}$

Various studies have shown that gender differences at the age of onset of puberty affect development of RE and with differences between biometric ocular parameters of males and females being reported, which suggests a possible correlation between gender and RE. ${ }^{34}$ Refractive error was found to be significantly higher in females $(56.7 \%)$ than males $(43.3 \%)(p=0.04)$ in the present study, a result similar to those observed in Lagos, ${ }^{6}$ South-South Nigeria, ${ }^{9}$ Kebbi State Nigeria $^{7}$ and Ethiopia. ${ }^{13}$

Studies have shown that the human eye grows by $5 \mathrm{~mm}$ from birth to 6 years, and by an additional $1 \mathrm{~mm}$ after 6 years until the age of 12 years. ${ }^{6}$ The prevalence of RE has been reported to increase to $2 \%$ by the age of 6 years and to $15 \%$ by the age of 15 years in the general population, 7 indicating the possibility of a relationship between increase in age and RE. This study found RE to increase with age and was highest 
(48.9\%) among children 11 to 13 years old. Similar findings were reported by Assefa et al. ${ }^{13}$ in Ethiopia and by Opubiri et al. ${ }^{9}$ in South-South Nigeria. However, a study in Enugu State, Nigeria, by Chuka-Okosa ${ }^{13}$ showed no significant association between RE and age. The large age range of 12-21 years used in the Enugu study could be responsible for the observed differences.

Myopia was the most prevalent (46.4\%) URE found in this study. This could be because of the fact that Onitsha is mainly an urban area and children in urban environment engage more in indoor and near work activities, such as higher usage of computers, smartphones and video games. ${ }^{31,32}$ Studies in Abia State ${ }^{8}$ and Bayelsa State, Nigeria, ${ }^{9}$ also found myopia to be the most prevalent refractive condition among primary school children aged between 7 and 17 years, and between 5 and 21 years. Although both studies were conducted in urban environments, variations in the prevalence rates could be attributed to the differences in age ranges, sample sizes and methodologies used. For instance, the current study used a sample size of 998 and an age range of 5-15 years, while the study by Ahuama and Atowa ${ }^{8}$ used a sample size of 4225 and an age range of 7-17 years. In addition, the present study was school based while Opubiri et al. ${ }^{9}$ was hospital based.

Studies in Tanzania and South Africa by Wedner et al. ${ }^{14}$ and Naidoo et al., ${ }^{15}$ respectively also showed myopia to be the most prevalent refractive condition among children aged between 5 and 15 years. Higher prevalence findings were reported in Singapore, ${ }^{35}$ China, ${ }^{36}$ Vietnam, ${ }^{37}$ Egypt $^{38}$ and Sudan. ${ }^{16}$ The higher prevalence of myopia recorded in those studies was attributed to the high prevalence of myopia in Asians and Arab children. Myopia is a common visual problem in schoolchildren globally, with early detection and management being highly indicated for educational, behavioural and quality-of-life benefits.

In this study, myopia was found to increase with age, starting from 8 to 10 years, which could possibly be because this age group is mostly in grade 5 and 6 which is the grade for preparing and writing entrance examination to high school in Nigeria leading to increased academic demand; thus, increasing the onset of myopia. A possible reason could be the onset of juvenile myopia, defined as myopia, with an onset between 7 and 16 years of age, primarily because of axial elongation that is usually caused by intensive near work. ${ }^{6}$ Ahuama and Atowa ${ }^{8}$ also reported myopic progression starting from 12 to 17 years in Abia State, Nigeria, with similar findings being recorded in the RESC survey in China, ${ }^{26}$ Chile $^{39}$ and South Africa, ${ }^{15}$ with the upward trend in myopia started from 13 to 14 years in the later.

Myopia was found to be significantly associated with males $(p=0.03)$, which could be because of the fact that the male children engage more in indoor activities, such as computer video games, chatting on phones, reading and writing, unlike the females who do more outdoor activities, such as domestic chores. Msiska et al. ${ }^{17}$ also found myopia to be significantly associated with males, while Wedner et al. ${ }^{14}$ and Kawuma and Mayeku ${ }^{18}$ reported contrary results in Tanzanian and Ugandan children, respectively. Muma et al. ${ }^{19}$ and Kumah et al. ${ }^{20}$ did not find any significant association between gender and myopia in Kenya and Ghanaian children, respectively, which could be because of the diverse age groups in the study samples. The prevalence of astigmatism varies in studies across populations, with racial factors being reported to be among the reasons for the differences observed in the prevalence of astigmatism worldwide. ${ }^{40}$ Early detection and correction of astigmatism are important, as most asthenopic symptoms that could lead to poor school performance are usually because of astigmatism. The prevalence of astigmatism of $-0.50 \mathrm{D}$ or worse found in this study was high. School children in urban areas engage more in near work and astigmatism is associated with increased near work. The prevalence is lower than 38.8\% reported in Lagos, Nigeria by Faderin and Ajaiyeoba. ${ }^{6}$ However, it is more comparable to $6.1 \%$ and $7.8 \%$ recorded in South-South Nigeria and Abia State, Nigeria, respectively (Table 5). The reasons for the discrepancies could be the inclusion of diverse age and ethnic groups in their study samples.

With-the-rule astigmatism was the most common type found in this study and this could be because it is commonly found in children ${ }^{16}$ Similar findings were reported by Atif et al. ${ }^{16}$ among Sudanese children aged between 5 and 15 years. Opubiri et al. ${ }^{9}$ and Naidoo et al. ${ }^{15}$ found astigmatism to increase with an increase in age in South-South Nigeria and South Africa, respectively. The present study did not find astigmatism to increase with age, the variability in findings possibly being attributed to ethical and racial differences. There was no gender difference in the prevalence of astigmatism in this study, this being similar to a report by Muma et al. ${ }^{19}$ in Kenya.

The prevalence of hyperopia was low (Table 5), which could be because of the study setting. Children in urban areas are more actively involved in near work and less outdoor activities, thus reducing their prevalence of hyperopia. ${ }^{19}$ The prevalence of hyperopia found in this study is higher than those reported in other Nigerian studies but lower than and comparable to those conducted in other African countries (Table 5). This wide variation could in part be because of the variations in the definitions of hyperopia, and/or age groups and ethnicities used in the various studies. For example, Ahuama and Atowa ${ }^{8}$ defined hyperopia as $+0.50 \mathrm{D}$ and higher, while the current study defined it as $2 \mathrm{D}$ and higher (Table 5). The study by Ahuama and Atowa ${ }^{8}$ also involved rural and older school children (7-17 years), which could have increased the prevalence of hyperopia, as it is well reported that hyperopia is more prevalent among children in the rural areas. ${ }^{17,19}$ Hyperopia was found to decrease with increasing age and was highest among children 5-7 years old. This is possibly because of the fact that this younger age group is prone to be more hyperopic, as their crystalline lens 
is still growing and they engaged in less reading and near work compared with the older age groups. Similar findings were reported in South-South, ${ }^{9}$ and Abia State, Nigeria, ${ }^{8}$ as well as in China, ${ }^{36}$ Chile $^{39}$ and South Africa. ${ }^{15}$ Females had more hyperopia than males in the present study, a result similar to that reported by Opubiri et al. ${ }^{9}$ in South-South, Nigeria and Msiska et al. ${ }^{17}$ in Malawi, but contrary to findings obtained by Kawuma and Mayeku ${ }^{18}$ in Kenya, and Maul et al. ${ }^{39}$ in Chile. The use of non-cycloplegic refraction in some of these studies could also have influenced the prevalence of hyperopia as this condition tends to produce more myopia and less hyperopia.

The prevalence of VI was 1.3\%, indicating that VI is relatively uncommon among primary school children in Onitsha. The prevalence is much lower than that reported in other Nigerian studies by Megbeleyin and Asana ${ }^{21}$ and comparable to that reported by Aijeyeoba et al. ${ }^{41}$ (Table 5). It is, however, not possible to make general overall comparisons among these results because of differences in ethnic backgrounds and methodologies used. Most (84\%) uncorrected VA of $\leq 20 / 40$ found in the present study was caused by RE, this result is consistent with other studies. ${ }^{9,15,19,36,38,39,42,43,44,45,46,47,48,49}$ Other causes of VI were amblyopia, retinal disorders, corneal opacity and albinism, which are similar to those reported in South Africa by Naidoo et al. ${ }^{15}$ and in Ghana by Kumah et al. ${ }^{20}$ This study also recorded no significant association between VI and gender, possibly because of the low prevalence of VI.

Several limitations of our study must be acknowledged. First, sometimes measuring VA and performing retinoscopy and auto-refraction on 5-year-olds and 6-year-olds was difficult because of poor attention span, lack of understanding and restlessness. Second, the relatively small sample size compared to other population-based RESC surveys and the fact that the sample for this study was drawn from an urban area limits generalisation of the results for the state or country. Future studies should include all children in Onitsha to completely understand RE and VI in this group.

In conclusion, this is the first RESC study undertaken in Onitsha, Anambra State, Nigeria and the results showed that the prevalence of RE and VI among primary school children were $9.7 \%$ and $1.3 \%$, respectively. These findings are comparable with some studies but vary from other reports and highlight the need to conduct local studies to establish regional baseline data to inform policy. The inclusion of training and information programmes on basic vision screening for teachers and school healthcare may ensure early detection of children with RE and VI.

\section{Acknowledgements}

The authors thank Onitsha North and South Education Secretaries, headmistresses, teachers and all the primary school children in Onitsha.

\section{Competing interests}

The authors declare that they have no financial or personal relationships that may have inappropriately influenced them in writing this article.

\section{Authors' contributions}

N.E.E. and K.P.M. made equal contributions to the writing of this article.

\section{References}

1. Dandona $L$, Dandona $R$, Srinivas $M$, et al. Blindness in the Indian state of Andhra Pradesh. Invest Ophthalmol Vis Sci. 2001;42:908-916.

2. Holden BA, Sulaiman S, Knox K. The challenge of providing spectacles in the developing world. J Com Eye Health. 2000;13:9-10.

3. Dandona $R$, Dandona $L$, Srinivas $M$, et al. Refractive error in children in a rura population in India. Invest Ophthalmol Vis Sci. 2002;43:6152-6162.

4. Adeoti CO. Beliefs and attitude towards spectacles. Nig J Clin Prac. 2009;12: 359-361.

5. Ayanniyi A, Mahmoud AO, Olatunji FO. Causes and prevalence of ocular morbidity among primary school children in Ilorin, Nigeria. Niger J Clin Prac. 2010;13:248-253.

6. Faderin MA, Ajaiyeoba Al. Refractive errors in primary school children in Nigeria. Niger J Ophthalmol. 2001;9:10-914. https://doi.org/10.4314/njo.v9i1.11913

7. Balarabe AH, Adamu I, Abubakar A. Vision screening to detect refractive errors in three selected secondary schools in Birnin Kebbi, North West, Nigeria. Sahel Med J. 2015;18:61-65. https://doi.org/10.4103/1118-8561.160799

8. Ahuama OC, Atowa UC. Distribution of refractive errors among school children in Abia State of Nigeria. J Nig Optom Assoc. 2004;11:25-28.

9. Opubiri I, Adedayo A, Megbalayin E. Refractive error pattern of children in Southsouth Nigeria: A tertiary hospital study. Sky J Med Sci. 2013;3:10-14.

10. Mitchell ML, Jolley JM. Research design explained. 7th ed. Belmont, CA: Wadsworth Publishers; 2010.

11. UN Habitat. Structure plan for Onitsha and Satellite Towns. 2009. UN HABITAT ISBN978-92-1-132117-3.

12. Ibenimo $\mathrm{O}$, Egbe CP. Screening for refractive error among primary school children in Bayelsa State, Nigeria. Pan Afr Med J. 2013;14-74. https://doi.org/10.11604/ pamj.2013.14.74.1345

13. Assefa WY, Wasie TB, Shiferaw D, Tsegaw A, Eshete Z. Prevalence of refractive errors among school children in Gondar Town, Northwest Ethiopia. MEAJO. 2012;194:372-376.

14. Wedner SH, Ross DA, Balira R, Kaji L, Foster A. Prevalence of eye diseases in primary school children in a rural area of Tanzania. Br J Ophthalmol. 2000;84:12911297. https://doi.org/10.1136/bjo.84.11.1291

15. Naidoo KS, Raghunandan A, Mashige KP, et al. Refractive error and visual impairment in African children in South Africa. Invest Ophthalmol Vis Sci. 2003;44:3764-3770. https://doi.org/10.1167/iovs.03-0283

16. Atif $A B$, Talha AK, Elmadina AM. Refractive errors status among children examined at Optical Centre in Khartoum State. Sud J Ophthalmol. 2016;8:10-13. https://doi. org/10.4103/1858-540X.184236

17. Msiska V, Njuguna M, Kariuki M. Magnitude and pattern of significant refractive errors in primary school children of Ntcheu, a rural district in Malawi. East Afr J Ophthalmol. 2009;15:18-20.

18. Kawuma M, Mayeku R. A survey of the prevalence of refractive errors among children in lower primary schools in Kampala district. Afr Health Sci. 2002;2: 69-72.

19. Muma M, Kariuki MM, Kimani K. Prevalence of significant refractive errors in primary school children in Makueni district, Kenya. East Afr J Ophthalmol. 2007;13:48-51.

20. Kumah BD, Ebri A, Abdul-Kabir M, et al. Vision in private school children in Ghana. Optom Vis Sci. 2013;90:1456-1461. https://doi.org/10.1097/OPX.0000000000000099

21. Megbelayin OE, Asana EU. Visual impairment among school children-calabar vision screening survey in secondary schools. Internet J Ophthalmol. 2010;10:18-20.

22. Mohammed AG, Wasfi El, Abdel Khalek EM. Refractive error among primary school children in Assuit district, Egypt. J Educ Prac. 2014;5:101-113.

23. Nebiyat K, Alemayehu W, Tigist SW. Refractive errors among school children in Addis Ababa, Ethiopia. J Ophthalmol East Afr. 2015;2:57-62.

24. Jafer K, Abomesh, G. Prevalence of refractive error and visual impairment among rural school-age children of Goro District, Gurage Zone, Ethiopia. Ethiop J Health Sci. 2014;24:353-358. https://doi.org/10.4314/ejhs.v24i4.11

25. Ovenseri-Ogbomo GO, Assien R. Refractive error in school children in Agona Swedru Ghana. S Afr Optom. 2010;69:86-92. https://doi.org/10.4102/aveh. v69i2.129

26. Ovenseri-Ogbomo GO, Omuemu VO. Prevalence of refractive error among school children in the Cape Coast Municipality, Ghana. Clin Optom. 2010;2:59-66. https://doi.org/10.2147/OPTO.S10583 
27. Semanyenzi SE, Karimurio J, Nzayirambaho M. Prevalence and pattern of refractive errors in high schools of Nyarugenge district. Rwandan Med J. 2015;723:81-83.

28. Balogun M. Refractive errors in primary school children in Lagos Mainland Dissertation for the award of a fellowship diploma of the National post graduate medical college in Ophthalmology, Nigeria. 1999; p. 39-42.

29. Nkanga DG, Dolin P. School vision screening program in Enugu, Nigeria: Assessment of referral criteria for error of refraction. Niger J Ophthalmol. 1997;5:34-40.

30. Yoloye MO. Patterns of visual defects and eye diseases among primary schoo children in Ibadan, Nigeria. Dissertation for the award of a fellowship diploma of children in Ibadan, Nigeria. Dissertation for the award of a fellowship diploma of
the National Post Graduate Medical College in Ophthalmology. 1991; p. 35-37.

31. Wen G, Tarczy-Hornoch K, McKean-Cowdin R, et al. Prevalence of myopia, hyperopia and astigmatism in Non-Hispanic White and Asian Children: Multiethnic Paediatric Eye Disease Study. Ophthalmology. 2013;120:2109-2116. https://doi.org/10.1016/j.ophtha.2013.06.039

32. Hashemi H, Abbastabar H, Yekta A, Heydarian S, Khabazkhoob M. The prevalence of uncorrected refractive errors in underserved rural areas. J Curr Ophthalmol. 2017;29:1-5. https://doi.org/10.1016/j.joco.2017.02.007

33. Resnikoff S, Pascolini D, Mariotti SP. Global magnitude of visual impairment caused by uncorrected refractive errors in 2004. Bull World Health Organ 2008;86:63-70. https://doi.org/10.2471/BLT.07.041210

34. O'Donoghue L, McClelland JF, Logan NS, Rudnicka AR, Owen CG, Saunders KJ. Refractive error and visual impairment in school children in Northern Ireland. Br J Ophthalmol. 2010;94:1155-1159. https://doi.org/10.1136/bjo.2009.176040

35. Saw SM, Gazzard G, Au Eong KG, Tan TH. Myopia: Attempts to arrest progression Br J Ophthalmol. 2002;86:1306-1311. https://doi.org/10.1136/bjo.86.11.1306

36. Zhao J, Pan X, Sui R, Munoz SR, Sperduto RD, Ellwein LB. Refractive error study in children: Results from Shunyi District, China. Am J Ophthalmol. 2000;129:427-435. https://doi.org/10.1016/S0002-9394(99)00452-3

37. Paudel $P$, Ramson $P$, Naduvilath $T$, et al. Prevalence of vision impairment and refractive error in school children in Ba Ria - Vung Tau province, Vietnam. Invest Ophthalmol Vis Sci. 2004;45:793-799.

38. Gamal AN, Ahmed AT, Yehia Sala EM, Rania Ahmed Abdel AS, Asmaa MM Prevalence of visual impairment and refractive errors in children in South Sinai, Egypt. Ophthalmic Epidemiol 2015;22(2):246-252. https://doi.org/10.3109/0928 6586.2015.1056811
39. Maul E, Barroso S, Munoz SR, Sperduto RD, Ellwein LB. Refractive error study in children: Results from La Florida, Chile. Am J Opthalmol. 2000:129:445-454. https://doi.org/10.1016/S0002-9394(99)00454-7

40. Mahjoob M, Heydarian S, Nejati J, Ansari-Moghaddam A, Ravandeh N. Prevalence of refractive errors among primary school children in a tropical area, South Eastern Iran. Asian Pacific J Tropic Biomed. 2016;6:181-184. https://doi. org/10.1016/j.apjtb.2015.10.008

41. Ajaiyeoba Al, Isawumi MA, Adeoye AO, Oluleye TS. Prevalence and causes of blindness and visual impairment among school children in south-western Nigeria. Ann Afr Med J. 2006;4:197-203.

42. Desalegn A, Tsegaw A, Shiferaw D, Woretaw H. Knowledge, attitude, practice and associated factors towards spectacles use among adults in Gondar town northwest Ethiopia. BMC Ophthalmol. 2016;16:184. https://doi.org/10.1186/ s12886-016-0357-3

43. World Health Organization. Cumulative official updates to ICD-10 Delhi 2008 [cited 2016 Feb 04]. Available from http://www.who.int/classifications/icd/ OfficialWHOUpdatesCombined1996-2008VOLUME.pdf

44. Chuka-Okosa CM. Refractive error among students of a post primary institution in a rural community in south eastern Nigeria. West Afr J Med. 2005;24:62-65. https://doi.org/10.4314/wajm.v24i1.28166

45. Abebe B. Unilateral blindness and low vision due to strabismic amblyopia. Ethiop J Health Dev. 2000;14:109-112.

46. Yoseph W, Samson B. Screening for ocular abnormalities and subnormal vision in school children of Batajira town, south Ethiopia. Ethiop J Health Dev. 2002;16:1657-1661.

47. Taha AO, Ibrahim SM. Prevalence of manifest horizontal strabismus among basic school children in Khartoum City, Sudan. Sudanese J Ophthalmol. 2015;7:53-57. https://doi.org/10.4103/1858-540X.169437

48. Akpe BA, Abadom EG, Omoti EA. Prevalence of amblyopia in primary school pupils in Benin City, Edo State, Nigeria. Afr J Med Health Sci. 2015;14:110-114. https:// doi.org/10.4103/2384-5589.170174

49. Kassa T, Daegu GA. Prevalence of refractive errors in pre-school and school children of Debark and Kola Diba towns, North-Western Ethiopia. Ethiop J Health Dev. 2004;17:117-124. 